\section{O DESPORTO INADEQUADO À NATUREZA FEMININA: PRELÚDIOS DO FUTEBOL FEMININO NO PARANÁ (1934-1951)}

THE INADEQUATE SPORT FOR FEMALE NATURE: PRELUDES TO WOMEN'S SOCCER IN PARANÁ (1934-1951) C己

EL DEPORTE INADECUADO A LA NATURALEZA FEMENINA: EL INICIO DEL FÚTBOL FEMENINO EN PARANÁ (1934-1951) C己

doi' https://doi.org/10.22456/1982-8918.118240

Joana Caroline Corrêa da Silva*<joana.carocosi@gmail.com>

André Mendes Capraro* <andrecapraro@gmail.com>

*Universidade Federal do Paraná. Curitiba, PR, Brasil.
Resumo: Quando comparamos temporalmente os marcos no desenvolvimento do futebol feminino e do masculino, podemos notar diferenças com origens para além dos gramados. Na tentativa de compreender melhor o fenômeno do futebol feminino, este artigo descreve e analisa a sua trajetória no Paraná até 1951. Para isso, foram utilizados alguns periódicos da hemeroteca digital brasileira e quatro telegramas encontrados no Arquivo Público do Paraná acerca de um pedido de autorização para realização de uma partida de futebol feminino em Curitiba. Após analisar as fontes, constatou-se que o futebol de mulheres esteve ligado a práticas artísticas a partir de 1934, e que seu ineditismo como esporte no Paraná aconteceu em 1951 no estádio Durival de Britto e Silva com as equipes gaúchas Amazonas e Tiradentes, em um contexto de imposições, contradições e desobediências civis.

Palavras-chave: História do século XX. Futebol. Mulheres.
Recebido em: 09 set. 2021 Aprovado em: 12 jan. 2022 Publicado em: 09 fev. 2022

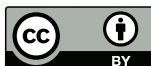

Este é um artigo publicado sob a licença Creative Commons Atribuição 4.0 Internacional (CC BY 4.0). 


\section{INTRODUÇÃO}

O ano era 1951. Pós-Segunda Guerra Mundial e em um momento de modernização dos meios de produção brasileiros, o Paraná enfrentava as decorrências do aumento populacional causado pelas intensas correntes migratórias (PRIORI et al., 2012). É diante desse contexto que quatro telegramas foram trocados entre o Conselho Regional de Desportos do Paraná (CRD/PR) e o Conselho Nacional de Desportos (CND). Esses documentos tratavam de um pedido de autorização para a realização de uma partida de futebol feminino em 18 de março daquele ano, solicitado pela entidade paranaense e negado pelo CND devido ao Art. 54 do Decreto-Lei 3.199/1941.

Nesse decreto-lei, cujo objetivo era estabelecer as bases de organização dos desportos, o Art. 54 delimitava que:

Às mulheres não se permitirá a prática de desportos incompatíveis com as condições de sua natureza, devendo, para este efeito, o Conselho Nacional de Desportos baixar as necessárias instruções às entidades desportivas do país. (BRASIL, 1941).

Mediante a negativa emitida em telegrama nota-se que, naquele momento, o futebol não era considerado compatível às condições naturais das mulheres, e por tanto, era proibido. Contudo, foram encontrados indícios nos jornais paranaenses da época que revelam a ocorrência do futebol de mulheres ${ }^{1}$ durante a validade do decreto.

Criado em abril de 1941 na conjuntura do Estado Novo, o Decreto-Lei 3.199 foi a primeira proposta de Lei Orgânica para os esportes no Brasil. Em seu contexto de criação, com significativa presença do nacionalismo (PANDOLFI, 1999) e em um cenário fértil para os esportes (GOELLNER, 1999), a ação legislativa incorporou o projeto de sociedade almejado na época (MANHÃES, 2002). O presidente e o Ministro da Educação podiam escolher o responsável maior pelo CND, portanto, os governos nacionais, até a validade do decreto-lei (1979), tiveram um representante à frente do CND aliado aos seus ideais políticos. Não é à toa que essa intervenção é "[...] uma referência da ideologia política dos esportes", como apontado por Ribeiro et al. (2014, p. 81).

De modo geral, antes dos anos 1940 as práticas físicas para as mulheres foram baseadas em atividades de fortalecimento do corpo como preparo à reprodução (GOELLNER, 2005; MOURÃO, 2000). Ao longo desses anos as mulheres foram ganhando notoriedade no âmbito esportivo gradativamente, através do apoderamento de ambientes que antes eram exclusivamente ocupados por homens. Entretanto, isso não significa que usufruíram de plena liberdade, autonomia e poder em tais lugares, mas que através da sua participação puderam incitar paulatinas mudanças no cenário e nas percepções da sociedade. Ademais, o uso e monopólio de certas forças institucionais foram significativos nesse período no âmbito esportivo, como Elias e Dunning (1992, p. 392) abordam:

1 Apesar de existirem referenciais que diferenciam os termos "futebol feminino" e "futebol de mulheres", esses foram utilizados de modo sinônimo neste estudo. 
O equilíbrio de poder entre os sexos irá também variar a favor dos homens de acordo com o grau em que estes dispõem, em relação às mulheres, de mais hipóteses de ações unificadas, e sempre que os homens monopolizam o acesso e o controlo das principais determinantes das oportunidades sociais, em especial na economia e no Estado.

Nessa relação de forças, as ações das mulheres fora de seus espaços desenhados influenciavam diretamente e indiretamente as instituições civis - predominantemente masculinas. Essas, no que Ihes concernem, podiam tanto dificultar quanto facilitar a continuidade das ações, utilizando da sua legitimidade e poder social. Um exemplo dessa relação - facilitada - é visível pela realização dos Jogos da primavera, também conhecidos como Olimpíadas femininas (1949):

[...] encheram-se as praças desportivas de famílias e 'fans', um intenso movimento de consagração dos 'Jogos da Primavera', idealização e realização do Jornal dos Sports, na figura de Mário Filho², seu idealizador, que objetivava a propagação e a democratização da prática dos desportos pelas moças jovens. (MOURÃO, 2000, p. 14).

Porém, vale ressaltar que nem sempre a participação das mulheres foi benquista, já que o protagonismo delas poderia intimidar quando entendido como ameaça à boa maternidade (GOELLNER, 2021).

Diante do contexto social e legal apresentado, a motivação para a troca dos telegramas de 1951 e a própria existência deles suscitam algumas contradições, que fornecem evidências para a hipótese de que a validade do Decreto-Lei 3.199/1941 não correspondeu à inexistência do futebol de mulheres no Brasil ou do seu desenvolvimento e apoio social - ao menos inicialmente. Por tanto, na tentativa de entender as relações da lei versus desobediência civil neste fenômeno, este estudo objetiva descrever e analisar a trajetória do futebol feminino no Paraná, deslocando o estudo do eixo Rio-São Paulo buscando entender de modo mais abrangente a temática e contrapondo a legislação com outras fontes, no esforço de fugir de uma história simplista que não se atenta a outras evidências e considera apenas a história legal.

\section{PROCESSO METODOLÓGICO DE SELEÇÃO E ANÁLISE dAS FONTES}

Durante a exploração do acervo do CRD/PR, através da participação da autora no projeto de pesquisa Inteligência Esportiva da Universidade Federal do Paraná, a pasta intitulada "BR PR APPR PB061.Tel.FutFem.21" se destacou em meio a vários documentos presentes na mesma caixa. Nela foram encontrados quatro telegramas de 1951, trocados entre o CRD/PR e o CND a respeito do futebol feminino.

O Quadro 1 foi desenvolvido com o intuito de identificá-los e descrevê-los. 
Quadro 1 - Classificação e descrição dos telegramas.

\begin{tabular}{|c|c|c|c|c|c|}
\hline DATA & $\mathrm{I}^{3}$ & E. $A^{4}$ & RESP. $^{5}$ & DEST. $^{6}$ & RESUMO DO CONTEÚDO \\
\hline $\begin{array}{c}09 \text { de } \\
\text { março } \\
\text { de } 1951\end{array}$ & 1 & CRD/PR & $\begin{array}{l}\text { Domingos } \\
\text { Moro } \\
\text { (secretário) }\end{array}$ & CND & $\begin{array}{l}\text { Solicitou em caráter de urgência saber se } \\
\text { havia proibição para realização do futebol } \\
\text { feminino, por conta de uma partida já } \\
\text { programada em Curitiba. }\end{array}$ \\
\hline $\begin{array}{c}13 \text { de } \\
\text { março } \\
\text { de } 1951\end{array}$ & 2 & CND & $\begin{array}{l}\text { Guimarães } \\
\text { Mello } \\
\text { (secretário) }\end{array}$ & CRD/PR & $\begin{array}{l}\text { Resposta informando que expediu um } \\
\text { telegrama em } 13 \text { de dezembro de } 1950 \\
\text { para que as instruções que regulam o Art. } \\
54 \text { fossem seguidas, proibindo o futebol } \\
\text { feminino. }\end{array}$ \\
\hline $\begin{array}{c}14 \text { de } \\
\text { março } \\
\text { de } 1951\end{array}$ & 3 & CRD/PR & $\begin{array}{l}\text { Domingos } \\
\text { Moro } \\
\text { (secretário) }\end{array}$ & CND & $\begin{array}{l}\text { Solicitação de resposta urgente sobre } \\
\text { permissão da prática de futebol entre } \\
\text { mulheres, por conta de uma partida } \\
\text { marcada para o domingo sequente em } \\
\text { Curitiba. }\end{array}$ \\
\hline $\begin{array}{c}18 \text { de } \\
\text { março } \\
\text { de } 1951\end{array}$ & 4 & CND & $\begin{array}{l}\text { Guimarães } \\
\text { Mello } \\
\text { (secretário) }\end{array}$ & CRD/PR & $\begin{array}{l}\text { Informação da proibição da prática de } \\
\text { futebol feminino por conta do Art.54. }\end{array}$ \\
\hline
\end{tabular}

Fonte: BR PR APPR PB061 Tel. FutFem.21, CRD/PR, Arquivo Público do Paraná.

Desde o encontro com os documentos relatados, alguns questionamentos surgiram acerca do teor das mensagens, que motivaram a construção deste trabalho. Com o intuito de respondê-los, uma investigação nos periódicos da época foi realizada, visando contextualizar a prática esportiva estudada e compreender a sua trajetória no Paraná, bem como encontrar elementos que se relacionem com as informações contidas nos telegramas. Obtido êxito na empreitada, as fontes foram contrapostas e através das informações extraídas foi construída uma linha do tempo entre a primeira ocorrência encontrada nos periódicos e a última de $1951^{7}$.

Considerando o estudo organizado por Gerhaldt e Silveira (2009), define-se este trabalho como uma pesquisa documental, que utiliza como fontes de primeira mão os documentos do acervo do CRD/PR do Arquivo Público do Paraná (APP) e os periódicos consultados no acervo da Hemeroteca Digital da Biblioteca Nacional.

Bacellar (2008) apresenta uma categorização dos documentos que geralmente estão presentes nos arquivos públicos, da qual se considera aqui o telegrama enquanto correspondência do poder executivo, entendendo os conselhos desportivos como extensão dele. Já os periódicos servem a esta pesquisa como complemento e ferramenta de confronto. Luca (2008) alerta para a possibilidade de usá-los como meio de adquirir outro ponto de vista na pesquisa, ou até mesmo como modo de contraposição aos documentos governamentais.

As buscas nos periódicos da hemeroteca digital ocorreram com o termo "futebol feminino", restringindo a pesquisa no Paraná e sem recorte temporal. Dos 200 jornais paranaenses que constam na hemeroteca digital, apenas onze obtiveram ocorrência

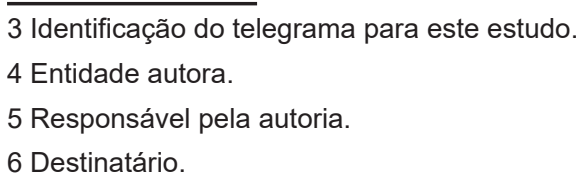


do termo utilizado. Após analisá-los, foram excluídas as ocorrências conforme o critério de exclusão ${ }^{8}$ e selecionadas aquelas que cumpriram o critério de inclusão ${ }^{9}$, resultando em 45, datadas de 1934 a 1951 e distribuídas em quatro jornais ${ }^{10}$ : O Dia ${ }^{11}$ (32); Diário da Tarde ${ }^{12}$ (7); Correio do Paraná: Órgão do partido liberal paranaense ${ }^{13}$ (4); Tarde $^{14}$ (2). Assim fixou-se o recorte temporal do estudo: 1934 a 1951.

Considerando que ainda poderiam existir notícias relevantes que não foram encontradas, fez-se necessário realizar duas pesquisas exploratórias na hemeroteca digital durante a construção do trabalho, utilizando termos relativos aos fatos encontrados durante a pesquisa inicial. As novas buscas, que tinham o intuito de construir uma narrativa mais embasada, seguiram os critérios metodológicos estabelecidos nesta seção.

As discussões foram divididas em duas partes. A primeira, intitulada "Entre acrobacias, balanças da morte e rãs humanas: dos picadeiros aos gramados", teve o intuito de descrever as aparições do futebol de mulheres no Paraná por meio das notícias de jornais encontradas até o evento citado nos telegramas (1934 - 1950). A segunda, "O ineditismo do futebol feminino no Paraná?", objetivou relacionar os telegramas e os periódicos da mesma época (1951).

\section{ENTRE ACROBACIAS, BALANÇAS DA MORTE E RÃS HUMANAS: DOS PICADEIROS AOS GRAMADOS}

[...] o Circo Irmãos Queirolo, anunciam os seus últimos espetáculos. [...] A noite, está reservado ao público um programa maravilhoso figurando além dos números inéditos a sensacionalíssima 'Balança da Morte' [...], destacando-se ainda a comedia 'Dança Mania' e o encerramento do campeonato de futebol feminino, que logrou tanto sucesso [...]. (O DIA, 7 jan. 1934, p. 2).

Não é novidade a ligação remota entre o futebol feminino e o circo. Bonfim (2019) relata que práticas como essa eram sempre exibidas nas segundas sessões dos espetáculos circenses. A companhia Irmãos Queirolo, que nesta pesquisa obteve dezenove correspondências entre 1934 e $1943^{15}$, foi identificada como um dos circos mais conhecidos de 1930 (BONFIM, 2019). Anúncios de outras companhias circenses renomadas também foram encontrados, os do Circo Irmãos Garcia ${ }^{16}$ e do Circo Nerino - que divulgou no jornal Correio do Paraná ${ }^{17}$ uma apresentação de futebol feminino entre shows de acrobatas, rãs humanas e anão de meio metro de altura, em um espaço capaz de abrigar mais de duas mil e quinhentas pessoas.

Os nomes das equipes das chamadas "moças da companhia" não eram aleatórios. Em Curitiba os torneios nos circos envolveram releituras dos clássicos

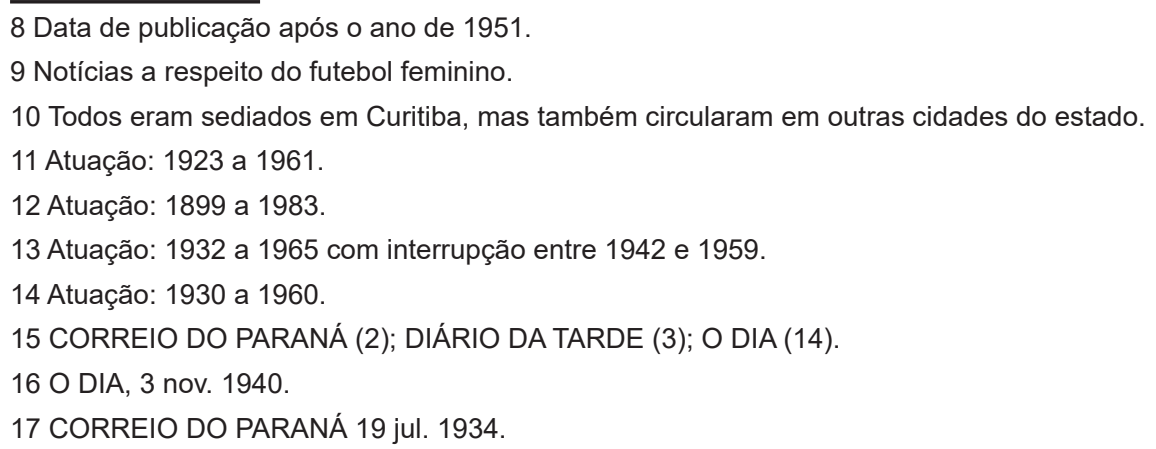


paranaenses entre os times do Coritiba, Athletico Paranaense, Britannia, Palestra Itália, Ferroviário, Juventus e Comercial ${ }^{18}$. Ademais, o futebol de mulheres ainda esteve presente em festas comemorativas, como na festa magna do clube Savoia, em Curitiba, entre churrascadas e partida entre solteiros e casados ${ }^{19}$.

Nesse arranjo em que o futebol feminino se encontrava, sua prática era formatada e vista essencialmente como uma exibição, em que a aplicação minuciosa das regras próprias da modalidade esportiva não fazia sentido. Assim, não se pode dizer que o futebol feminino era um esporte naquele momento, pois se configurava apenas como uma manifestação artística. O que motivava era a curiosidade do público e a excentricidade das participantes.

A ideia de exotismo em que o futebol de mulheres foi conformado nesses espaços conferiu e reforçou valor à prática, englobou-a como mercadoria, a associou de antemão aos corpos das mulheres e reforçou uma ideia de impossibilidade de o futebol - esporte - ser praticado por elas.

Desde então, o que começou como uma prática com foco no espectador passou gradativamente a se desenvolver como uma atividade voltada também às praticantes. De maneira geral, isso ocorreu em um momento que as mulheres começaram a atuar e se organizar mais no âmbito esportivo. Mourão (2000) mostra em sua pesquisa, por exemplo, que algumas jovens desportivas começavam a fundar clubes e a organizar os primeiros campeonatos femininos de basquete, natação e vôlei.

Em notícias do início de 1940, encontradas nos jornais paranaenses ${ }^{20}$, observam-se relatos de eventos nos maiores polos urbanos do Brasil da época, como o anúncio do jogo ocorrido no estádio do Pacaembu (SP) entre equipes femininas representantes do Cassino Realengo e do S. C. Brasileiro ${ }^{21}$, e os "prélios de futebol feminino" no Rio de Janeiro entre clubes organizados que pretendiam se reunir em uma Liga ${ }^{22}$.

Parece que o futebol feminino estava sendo sistematizado e normatizado em outros estados do país, portanto, adquirindo contornos esportivos.

A mudança dos picadeiros para os gramados se deu em um momento de efervescência política nacional e internacional. Isso explica a charge publicada no jornal O Dia, conforme Figura 1:

\footnotetext{
18 O DIA (3 jan. 1934; 4 jan. 1934; 5 jan. 1934; 6 jan. 1934). 19 O DIA (11 ago. 1937; 20 ago. 1937).

20 Em uma espécie de ruptura entre as naturezas das práticas, as notícias a respeito do futebol feminino nessa época começaram a aparecer em seções esportivas, diferentemente dos anúncios dessa prática nos circos e eventos sociais. 
Figura 1 - No mundo da bola

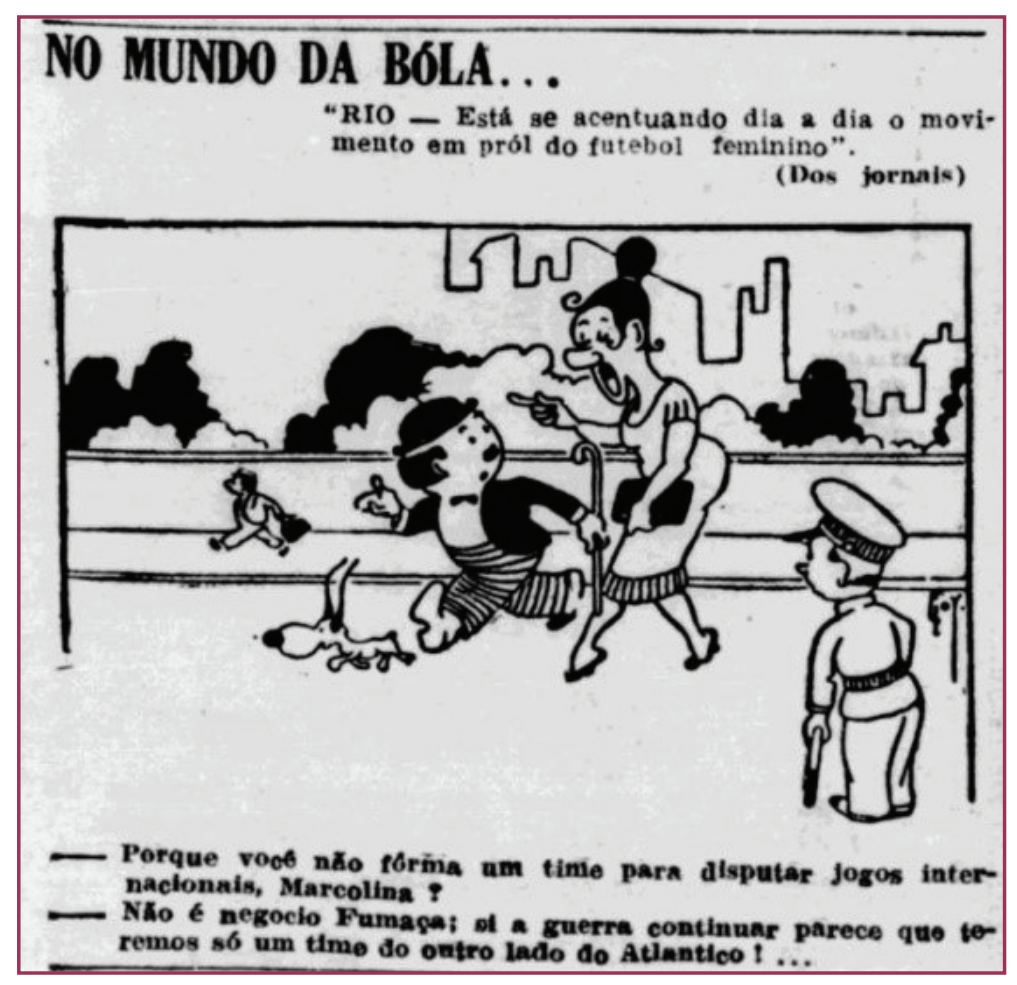

Fonte: O DIA (16 de abril de 1940, p.1)

Porém, mesmo que o futebol feminino estivesse se incorporando aos debates sociais e se desenvolvendo, não foi de uma hora para a outra que ocorreu a criação do Art. 54. A concepção de inadequação do futebol à mulher foi fruto de uma percepção que também tentava se estabelecer, visível na reprodução realizada pelo O $\mathrm{Dia}^{23}$ do texto publicado originalmente no jornal do Rio de Janeiro O imparcial. Nessa publicação, o Dr. Leite de Castro, dito como percursor do controle médico dos esportes no Brasil e notável autoridade em assuntos científico-esportivos, descreveu o futebol como falho considerando os critérios médicos, e quanto ao futebol feminino em específico:

Nada Ihes aproveita e, pelo contrário, proporciona-lhe alterações nas funções circulatórios e renais, além de perturbações estáticas que o exercício físico violento pode determinar na esfera genital [...] Só pode ser aplaudido, como exibição grotesca ou teatral ao sabor da curiosidade popular. (O DIA, 26 jun. 1940, p. 10).

Esse formato de manifestação, pautado na valorização da funcionalidade genital, visava "[...] legislar e defender, sob argumentos 'científicos', quais as práticas adequadas às mulheres" (KNIJNIK, 2003, p. 56.). Além disso, indicava que o lugar do futebol de mulheres devia equivaler aos formatos anteriores da prática, conformada como exibição exótica.

Tais concepções validaram notícias como esta:

O FUTEBOL FEMININO VAI ACABAR

RIO, 13 (O DIA) - Afirma-se que a $2^{\mathrm{a}}$ delegacia auxiliar está decidida a acabar de uma vez com o futebol feminino... Para isso serão fechados todos os clubes dessa especialidade. 
Está aí uma notícia magnifica, digna de melhores aplausos. O futebol feminino, como esporte, é desaconselhável, e, como passatempo, perigoso e... nocivo, embora haja 'teams' que gostem de dar verdadeiros 'bailes' nos adversários [...]. (O DIA, 14 fev. 1941, p.6).

A partir da publicação do Decreto-Lei as notícias acerca do futebol feminino se estagnaram durante quase uma década, foram noticiados apenas os feitos internacionais nesse meio tempo. Em uma publicação no Diário da $\operatorname{Tarde}^{24}$ foi informado que, apesar de proibido no Brasil, o futebol feminino estava em pleno vigor na Rússia. Foram citadas inclusive as modificações introduzidas nos nomes das posições táticas, como de ponteiros para "da ponta" e de dianteiros para dianteiras.

O interlúdio nas notícias do futebol de mulheres se encerrou somente no final de 1950. As novas publicações tratavam a respeito de uma partida de futebol feminino a ser promovida pela Associação dos Cronistas Esportivos do Paraná (ACEP/PR) no dia 19 de dezembro de 1950. O jornal O Dia informou, em 26 de novembro daquele ano (p. 8), que a ACEP/PR solicitara uma data para a realização do intento futebolístico à Federação Paranaense de Futebol (FPF), e esta, "através da palavra autorizada do seu atual presidente, Dr. José Cadilhe de Oliveira, não opôs qualquer obstáculo", mesmo que ainda tivesse que ter aprovação do conselho divisional da federação através de uma reunião. ${ }^{25}$.

Em 11 de dezembro, já com as negociações concluídas, a ocorrência do jogo era certa. "Espetáculo inédito e diferente" anunciava o jornal $A$ Tarde (p. 2). E não somente a capital paranaense aguardava a partida, pois, segundo o subtítulo da notícia do O Dia de 13 de dezembro de 1950 (p. 7), o interior do estado apresentava "um entusiasmo jamais visto". Mais adiante na publicação o jornal ainda informou: "[...] os primeiros telegramas do interior já chegaram. E eles solicitaram reservas de ingressos, numa demonstração de que virá muita gente para presenciar esse choque magistral".

Percebe-se o entusiasmo da mídia pela atenção dedicada ao evento, produzindo notícias que exploravam o dito ineditismo da partida. Afinal, seria a primeira vez que duas equipes compostas por mulheres entrariam em ação no Paraná, segundo os jornais. A excepcionalidade também se deu pelo fato de que a partida anunciada ditava o confronto entre "Corinthians"26 e "Vila Hilda ${ }^{27}$, times do Rio Grande do Sul que atuariam no Estádio Joaquim Américo Guimarães ${ }^{28}$.

A falta de notícias a respeito de práticas do futebol feminino do Paraná leva a crer que o estado não o possuía de forma desenvolvida ainda, ou não o notava com o mesmo empenho. As explicações e as razões podem ser diversas. O que podemos constatar é que o Paraná não se apresentava como um vanguardista brasileiro do futebol feminino.

24 DIÁRIO DA TARDE (14 fev. 1946).

25 O DIA (29 nov. 1950).

26 Foram encontradas notícias no O Dia (26 nov. 1950) informando que o jogo ocorreria entre os times Corintians e Rio Grande. No entanto, consideraram-se as notícias mais recentes, que divulgaram a outra formação citada.

27 Uma pesquisa exploratória na hemeroteca digital utilizando o termo "Vila Hilda" foi realizada. Considerando que ambos os nomes dos times estariam nas notícias, foi selecionado o que não apresentou variações de escrita entre os jornais já encontrados. Das nove ocorrências descobertas, foram eliminadas seis delas seguindo os critérios metodológicos e uma por já estar inclusa entre as fontes iniciais. As seleções foram: DIÁRIO DA TARDE (14 dez. 1950; 15 dez. 1950).

28 O DIA; DIÁRIO DA TARDE (14 dez. 1950). 
Em Pelotas/RS, alguns times femininos já se destacavam, como os que ACEP/ PR promovera para atuarem em Curitiba. Rigo et al. (2008) identificou-os como parte da história da cidade no pioneirismo da organização de times de futebol compostos exclusivamente por mulheres. Segundo a pesquisa desse autor, "as duas equipes foram fundadas praticamente juntas, em abril de 1950. A maioria das jogadoras era jovem, entre 13 e 18 anos, que pertencia à classe média baixa e residia nos próprios bairros onde os clubes estavam situados" (p. 177).

Em notícia ao título “Brotinhos' em confronto", que quase preenche uma página do jornal Diário da Tarde (14 dez. 1950, p. 3), é relatado sobre o entusiasmo para a partida: "[...] se observa preponderantemente uma reação simpática no seio da torcida feminina da capital, tão empolgada, em verdade como os representantes do sexo-forte". Em outro trecho da mesma notícia foi mencionado sobre "[...] um espírito de curiosidade que surpreendentemente admite como realidade a intromissão do belo sexo em um desporto que até aqui pelo menos vinha sendo de responsabilidade única dos homens". Nesse mesmo jornal no dia seguinte, em uma crônica ao título "Evas de chuteiras", tal inserção foi entendida como parte de um movimento que garantiu às mulheres direitos equiparados aos dos homens, o feminismo. Segundo ela, por resultado dessa mobilização, as mulheres:

[...] hoje fumam, guiam automóveis, dirigem taxis e caminhões, aprendem jiu-jitsu, e usam 'shooteira', disputando acirradas partidas de futebol, com o mesmo entusiasmo dos homens ou talvez com mais, e até 'xingam' o juiz quando este banca o Pereira Peixoto. (DIÁRIO DA TARDE, 15 dez. 1950, p. 3).

Nota-se que as notícias a respeito de tal feito invocam um olhar de curiosidade e em uma perspectiva masculina. Isso exemplifica a já citada participação de outros grupos sociais, auxiliando no desenvolvimento do futebol feminino, como também abre possibilidade de questionamento a respeito de tal ineditismo, afinal poderiam as mulheres já terem se organizado anteriormente e apenas não conseguirem o mesmo espaço nas manchetes por não possuírem significativa participação nas entidades civis. O que se pode garantir é que, nas dadas configurações, o jogo de 19 de dezembro de 1950 validaria socialmente a realização de uma partida de futebol exclusivamente composto por mulheres em solo paranaense, e era isso que a ACEP/ PR parecia almejar, pois havia inclusive a intenção de formular uma tabela de preços para que as entradas fossem acessíveis a todos os torcedores ${ }^{29}$.

Porém, o evento não ocorreu.

Em 17 de dezembro de 1950 o jornal O Dia estampou uma nota, escrita pela ACEP/PR, que anunciava o adiamento da partida. Como justificativa, a associação alegou que a data coincidia com as festividades de final do ano - mesmo que tivesse sido votada. Outro ponto argumentado foi o alto custo para o empreendimento, já que o programa dos times incluía paradas no interior paranaense e em Santa Catarina.

\section{O INEDITISMO DO FUTEBOL FEMININO NO PARANÁ?}

Após a nota publicada, o termo pesquisado volta a ter correspondência em 1951. No dia 14 de março desse ano, o jornal Diário da Tarde publicou um texto 29 DIÁRIO DA TARDE (14 dez. 1950). 
assinado com as siglas "C.G.L". Tal escrito anunciava mais um feito da ACEP/PR ao promover a viagem dos times femininos do Rio Grande do Sul à Curitiba. Ao título "Pela primeira vez nesta capital", O Dia ${ }^{30}$ também divulgou tal realização e informou que o jogo ocorreria em 18 de março de 1951.

Acerca do interesse popular pelo evento, $\mathrm{O} \mathrm{Dia}^{31}$ relatou que a procura de ingressos era grande, do mesmo modo os pedidos por reservas. Já o jornal Diário da

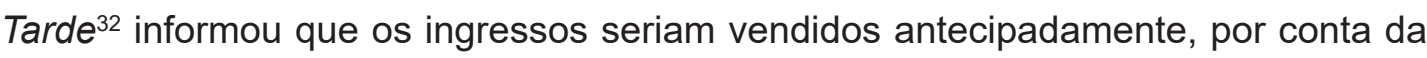
intensa procura. Quanto ao local que abrigaria os interessados, diferentemente do ano anterior, o cenário seria um dos palcos da Copa do Mundo de futebol - masculina - de 1950, o estádio Durival de Britto e Silva, chamado também de Vila Capanema.

\footnotetext{
Quando as duas equipes de moças pisarem o gramado de Vila Capanema, vai ser uma apoteose. [...]

Para se ter uma ideia do quanto o embate está empolgando, basta dizer-se que até sábado a lotação do 'Durival de Brito' estará tomada.

Tudo indica que a maior praça de esportes do sul do Brasil abrigará uma assistência colossal [...]. (O DIA, 16 mar. 1951, p. 7).
}

Os elementos presentes nos quatro documentos encontrados no Arquivo Público do Paraná direcionam para o entendimento de que os telegramas tratavam de uma conversa, iniciada pelo CRD/PR (telegrama 1) consultando o CND sobre a possibilidade de ocorrência de uma partida de futebol feminino no dia 18 de março de 1951 na capital paranaense, tal como o evento encontrado através dos jornais. Como já antecipado, a partida foi proibida pelo CND (telegrama 2 e 4).

Destaca-se o caráter de urgência solicitado pelo CRD/PR na resposta ao pedido, bem como o encaminhamento de um novo telegrama no dia 14 de março, com a mesma solicitação já realizada no dia 09, dando indícios de que o esclarecimento a respeito da legalidade da partida era importante para a entidade naquele momento.

Mesmo que desde novembro de 1950 no Rio Grande do Sul a proibição já fosse de conhecimento geral (RIGO et al., 2008), e considerando que o CND já houvera esclarecido tal proibição no dia 13 de dezembro de 1950 (telegrama 2) - um dia antes da ACEP/PR notificar cancelamento do evento programado para 19 de dezembro de 1950 -, o CRD/PR solicitou esclarecimento também em 1951. Considerando ainda o intervalo de tempo entre a primeira solicitação do CRD/PR e a primeira resposta postada pelo CND, é possível que o telegrama com a proibição da partida tenha chegado às mãos do conselho paranaense antes da data de realização do jogo de 1951.

Uma coisa era certa: mesmo com a imprecisão textual do Art. 54, o futebol feminino não era autorizado pelo CND. A entidade já havia deixado isso claro.

Mesmo assim, o ensaio de Rubens Padilha Mendes intitulado "Espetáculo Degradante" foi publicado, indicando a realização da partida. Nele, Rubens anunciou que: 
Por dolorosa coincidência, Curitiba foi palco, no Domingo de Ramos, ao iniciar-se a Semana Santa, evocativa da sublime tragédia do Gólgota, em que Deus se imulou na cruz pela redenção da humanidade, de um degradante espetáculo rotulado de esportivo [...]. (A TARDE, 21 mar. 1951, p.4).

Segundo essa publicação, pode-se considerar que a partida não foi bem quista por parte da população. Esse texto vai de encontro a algumas concepções já descritas, nas quais o futebol desacorda com a os ideais da delicadeza natural da mulher e recato feminino.

Entretanto, concluir essa seção consagrando a realização do dito primeiro jogo de futebol feminino no Paraná dessa forma não se faz suficiente. Muitas perguntas não foram respondidas acerca desse evento ainda, por isso fez-se necessário continuar a inquirição.

A fim de encontrar mais informações a respeito das equipes participantes e das particularidades do evento, foi realizada uma busca com os nomes do estádio onde a partida estava programada ${ }^{33}$. A partir das notícias encontradas com datas anteriores ao evento já foi possível identificar indícios acerca da proporção que ele adquiria.

Para o dito espetáculo inédito, uma tabela de preços foi divulgada ${ }^{34}$, contendo 400 cadeiras cobertas disponíveis, visando à comodidade dos espectadores ${ }^{35}$. (Ver Figura 2)

Figura 2 - Tabela de valores dos ingressos.

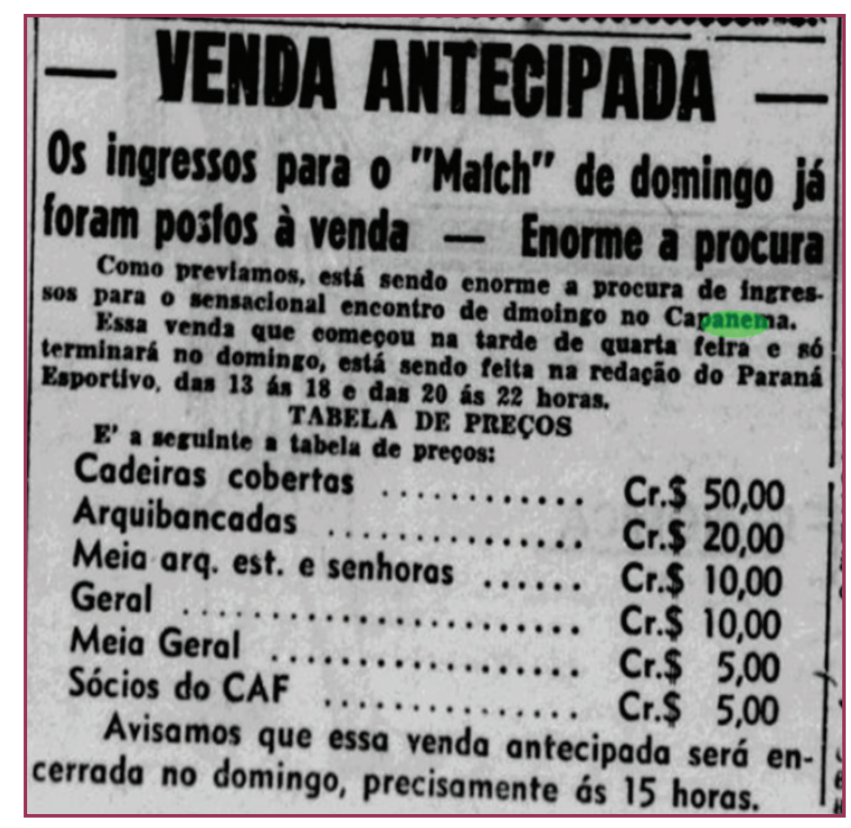

Fonte: O DIA (16 de março de 1951, p. 6)

A título de comparação, em 25 de fevereiro de 1951 o jornal O Dia publicou os preços para os jogos a serem promovidos pela FPF naquele ano, entre os quais o valor para as arquibancadas era de $\mathrm{Cr}$ \$10,00 e para o geral Cr. $\$ 5,00$.

\footnotetext{
33 Os termos "Durival" e "Capanema" foram utilizados. Entre os resultados, foram selecionados aqueles que cumpriram com os critérios metodológicos e ainda não haviam sido encontrados na pesquisa inicial. Restaram 13 notícias, datadas entre 11 e 20 de março de 1951: O DIA (8); DIÁRIO DA TARDE (5). 
As equipes gaúchas, que já tinham rivalidade por conta de confrontos anteriores $^{36}$, chegariam em dois aviões da Varig no aeroporto Afonso Pena, que havia sido liberado para voos comerciais apenas alguns anos antes, após o fim da Segunda Guerra Mundial. Além disso, foi divulgado que ocorreria uma partida preliminar entre times masculinos. Segundo O Dia, de 17 de março de 1951, tal partida seria realizada entre os times suburbanos do Ipe e Novo Mundo, já o Diário da Tarde escreveu na mesma data que o confronto seria entre equipes da terceira divisão de Curitiba: Tebê e Vila Pinto. Sobre a arbitragem, o jornal O Dia divulgou em 14 de março de 1951 que o árbitro da partida seria Ataide Santos, entretanto, o nome definido acabou sendo o de Kalil Karam ${ }^{37}$.

Três dias antes do jogo programado, uma notícia relatou que o entusiasmo para o domingo (18) não era sem razão:

E tudo isso se justifica, porquanto um encontro dessa natureza nunca foi proporcionado ao mundo esportivo paranaense. [...]

Segundo notícias recém enviadas de Porto Alegre, todas as moças encontram-se em superior forma física e técnica, já tendo encerrados seus primeiros preparativos. [...]

Já tivemos visto jovens pratricias praticando com êxito outros esportes, tais como vôlei, bola ao cesto, tenis, pingue - pongue, atletismo, natação.

Todavia, nunca vimos dois times femininos exibindo-se numa renhida partida de futebol. [...] (O DIA, 15 mar. 1951, p. 7)

Segundo o periódico $\mathrm{O} \mathrm{Dia}^{38}$, outras cidades do Paraná programavam caravanas para prestigiar o jogo, vindas de Paranaguá, Antonina, Morretes, Araucária, Campo Largo, Palmeira, São José, Jacarezinho e Londrina. Ainda nesse jornal, uma foto de uma das integrantes das equipes femininas foi impressa (ver Figura 3), sem especificar seu nome.

Figura 3 - Foto de uma das jogadoras

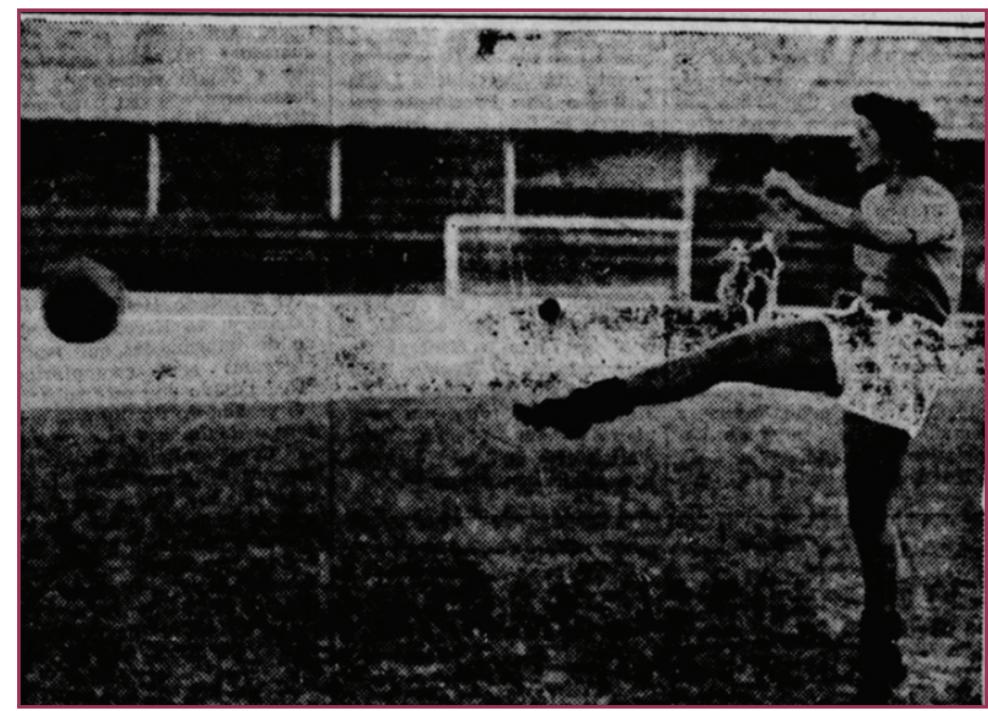

Fonte: O DIA (14 de março de 1951, p. 7)

36 O DIA (14 mar. 1951; 16 mar. 1951)

37 O DIA (17 mar. 1951).

3814 mar. 1951. 
Já na data do evento, outra foto foi publicada, vista na Figura 4, com a legenda: "Eis aí uma graciosa 'crack-girl' [...] Uma boa manejadora da 'Goa', que certamente, conquistara muitos 'fans' em nossa capital".

Figura 4 - "Crack-girl"

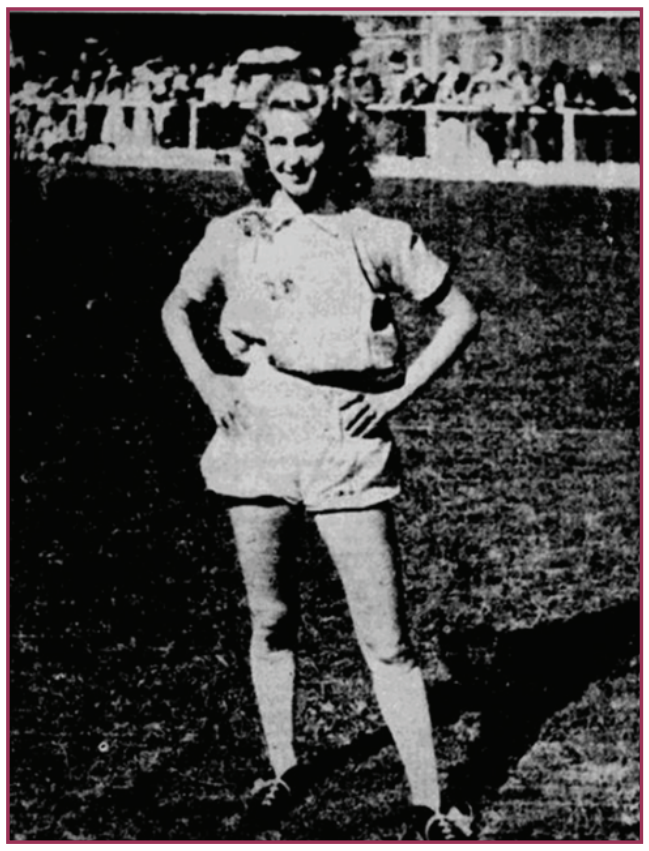

Fonte: O DIA (18 de março de 1951, p.9)

A partir da pesquisa exploratória também foi possível encontrar notícias com datas após a realização do evento. Através delas foi identificado que o jogo ocorreu entre as equipes Amazonas e Tiradentes, de Porto Alegre. Segundo Rigo (2008), elas figuravam entre as equipes femininas que realizavam partida naquele momento no Rio Grande do Sul, assim como o Vila Hilda, Corinthians e Renner.

Desse embate com dois gols, marcados por Naná e Arita, o Tiradentes foi consagrado campeão ${ }^{39}$.

\section{ESPETÁCULO INÉDITO EM “VILA CAPANEMA"}

[...] Na parte técnica não era de grandes resultados, uma vez que se trata de um quadro que pela razão de ser feminino não tem meios de conseguir elementos como acontece geralmente com o futebol em si. No entanto pode se destacar lances inúmeros que merecem registro [...]. (A TARDE, 19 mar. 1951, p.2).

Além das goleadoras do jogo, a escalação do time campeão foi completada por: Irma; Gringa; Bigode; Maria; Gladis; Vergínia; Tereza; Ruth e Eliana. Já a do Amazonas foi composta por: Eva; Clarel; Sonia; Iolanda; Geada; Verinha; Carmen; Selma; Norma; Quarena e Eliana ${ }^{40}$. 
Figura 5 - Foto de um dos times

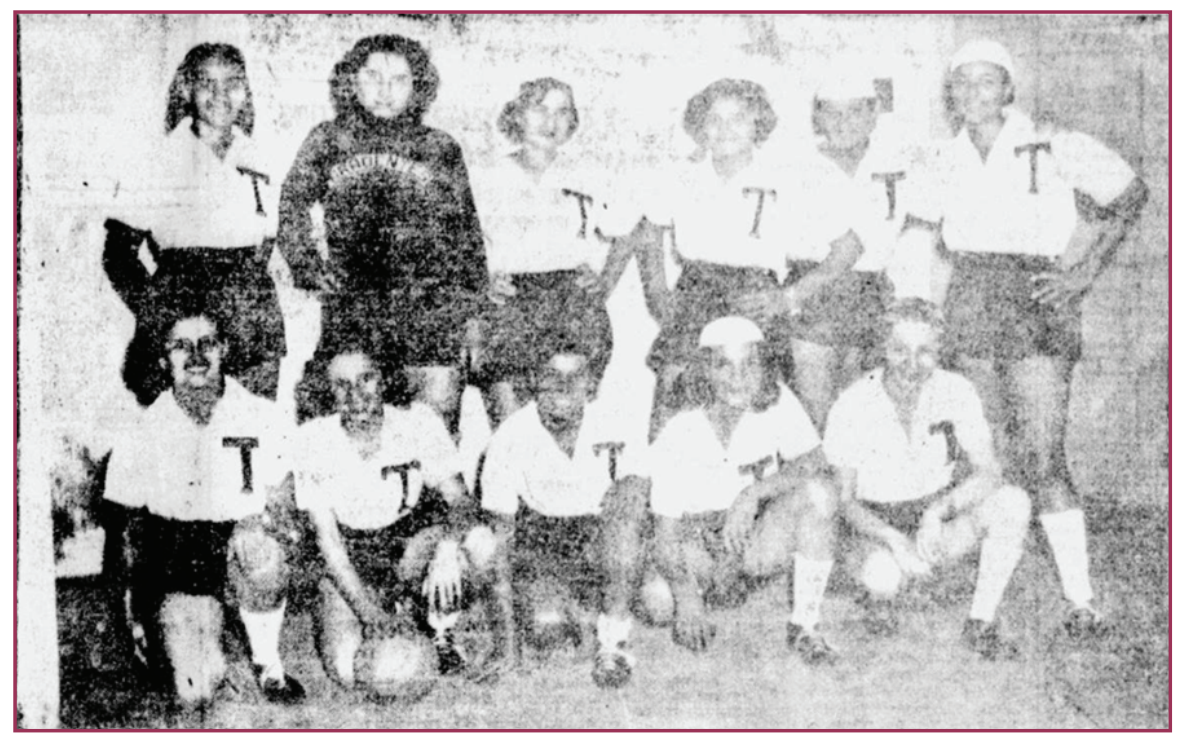

Fonte: DIÁRIO DA TARDE (19 de março de 1951, p. 3)

Apesar de não haver legenda, a foto da Figura 5 parece ser um registro do time Tiradentes, campeão do jogo. No texto que acompanhou a imagem foi relatado que, a despeito da chuva ocorrida antes da partida, foram arrecadados 105.312,00 cruzeiros: "As moças demonstraram que, apesar do estado quase impraticavel do gramado, que sabem jogar futebol, Um futebol bonito e com muita graça [...]." (DIÁRIO DA TARDE, 19 mar. 1951, p.3).

Após o feito na capital paranaense, os dois times ainda eram aguardados em Florianópolis, segundo notícia do O Dia ${ }^{41}$. Já em 27 de dezembro (p. 6), na última reportagem do ano a respeito da temática, o mesmo jornal divulgou notícia do Rio de Janeiro, discorrendo brevemente sobre a proibição dos "jogos de foot-ball entre o 'sexo frágil'” feita pelo CND.

Apesar de os relatos serem relevantes para traçar a trajetória do futebol feminino no Paraná, é necessário olhar com cautela aqueles acerca do ineditismo da prática em solo paranaense em 1950 e 1951, afinal, como colocado por um membro da ACEP/PR em um dos achados que discorre sobre o feito da associação em trazer o futebol feminino à Curitiba: "elogio de boca própria, é vitupério"42. Por vezes, a mesma voz que noticiava era a que tinha interesses para que o evento acontecesse, e por mais que isso não desvalide o teor das notícias ou aquilo que elas nos mostram além das palavras, deve-se haver certo afastamento de modo a evitar juízos indevidos.

Por fim, sabe-se que o estádio lotou, a população paranaense participou, e o jogo aconteceu!

\section{CONSIDERAÇÕES FINAIS}

O futebol de mulheres no Brasil constituiu-se de ações descoordenadas e não progressivas, em um contexto carregado de ideais que embasavam os discursos 
a respeito do que era cabível à mulher, ao seu corpo e às suas condutas. Naquela época o futebol correspondia naturalmente ao esporte praticado pelos homens, enquanto o futebol feminino era uma mera versão, vista como "anatural".

Entende-se que o Paraná consagrou o futebol de mulheres enquanto prática esportiva no dia 18 de março de 1951 em Curitiba, durante a partida entre os times de Porto Alegre inteiramente compostos por mulheres: Amazonas e Tiradentes. Se os esportes são movidos pela busca da vitória contra um oponente, eles ganham ainda mais sentido se vistos por terceiros, em uma procura pela palpável consagração. Logo, o alcance do evento de 1951 promoveu o futebol de mulheres ao elevar, aos olhos da população e das entidades, a vitória do time Tiradentes. A prática que anteriormente era sucessivamente divulgada como parte de um grande show, repleto de bizarrices e participações cômicas, ganhou, naquele momento, efetivo contorno esportivo muito antes da sua regulamentação.

Mesmo com a proibição específica do CND e a sua vontade de deter o futebol feminino, as entidades civis do Paraná incentivaram e auxiliaram a efetivação do feito, em um ato de desobediência civil. Evidenciando que a lei era um anseio político e estratégico, e não necessariamente popular.

Porém, por mais que ocorressem transgressões, as tentativas de conter o desenvolvimento do futebol deixaram efeitos, pois a utilização da máquina estatal coibiu a livre participação, construção e regulamentação do futebol feminino de forma natural na época. Não se podem calcular os impactos diretos e indiretos das imposições legais e oficiais ocorridas, mas pode-se notar que entre a década de 1940 e 1950 o futebol feminino já caminhava rumo aos moldes esportivos.

\section{REFERÊNCIAS}

A TARDE (PR), Curitiba, 11 dez. 1950, p. 1. Hemeroteca digital, Biblioteca Nacional. Disponível em: http://bndigital.bn.gov.br/hemeroteca-digital/. Acesso em: 9 ago. 2021

A TARDE (PR), Curitiba, 19 mar. 1951, p. 2. Hemeroteca digital, Biblioteca Nacional. Disponível em: http://bndigital.bn.gov.br/hemeroteca-digitall. Acesso em: 9 ago. 2021

A TARDE (PR), Curitiba, 21 mar. 1951, p. 4. Hemeroteca digital, Biblioteca Nacional. Disponível em: http://bndigital.bn.gov.br/hemeroteca-digital/. Acesso em: 9 ago. 2021

BACELLAR, Carlos. Fontes documentais: uso e mau uso dos arquivos. In: PINSKY, Carla Bassanezi (org.). Fontes Históricas. 2. ed. São Paulo: Contexto, 2008. p. 23-80.

BONFIM, Aira Fernandes. Football Feminino entre festas esportivas, circos e campos suburbanos: uma história social do futebol praticado por mulheres da introdução à proibição (1915- 1941). 2019. 213 f. Dissertação (Mestrado em História Política e Bens Culturais) - Escola de Ciências Sociais, Fundação Getulio Vargas, Rio de Janeiro, 2019. Disponível em: https://bibliotecadigital.fgv.br/dspace/handle/10438/28563. Acesso em: 23 jul. 2020. 
BRASIL. Decreto-lei no 3.199, de 14 de abril de 1941. Estabelece as bases de organização dos desportos em todo o país. Diário Oficial da República Federativa do Brasil, Rio de Janeiro, 16 abr. 1941, Seção 1, p. 000.

CONSELHO NACIONAL DE DESPORTOS [Telegrama]. Destinatário: Conselho Regional de Desportos do Paraná. Acervo do Conselho Regional de Desportos do Paraná, Arquivo Público do Paraná. Registro: BR PR APPR PB061.Tel. FutFem.21. Curitiba, 13 mar. 1951.

CONSELHO NACIONAL DE DESPORTOS [Telegrama]. Destinatário: Conselho Regional de Desportos do Paraná. Acervo do Conselho Regional de Desportos do Paraná, Arquivo Público do Paraná. Registro: BR PR APPR PB061.Tel. FutFem.21. Curitiba, 18 mar. 1951.

CONSELHO REGIONAL DE DESPORTOS DO PARANÁ [Telegrama]. Destinatário: Conselho Nacional de Desportos. Acervo do Conselho Regional de Desportos do Paraná, Arquivo Público do Paraná. Registro: BR PR APPR PB061.Tel. FutFem.21. Curitiba, 9 mar. 1951.

CONSELHO REGIONAL DE DESPORTOS DO PARANÁ [Telegrama]. Destinatário: Conselho Nacional de Desportos. Acervo do Conselho Regional de Desportos do Paraná, Arquivo Público do Paraná. Registro: BR PR APPR PB061.Tel. FutFem.21. Curitiba, 14 mar. 1951.

CORREIO DO PARANÁ: Órgão do Partido Liberal Paranaense (PR), Curitiba, 19 jul. 1934, p. 5. Hemeroteca digital, Biblioteca Nacional. Disponível em: http://bndigital.bn.gov.br/ hemeroteca-digitall. Acesso em: 9 ago. 2021.

CORREIO DO PARANÁ: Órgão do Partido Liberal Paranaense (PR), Curitiba, 24 ma. 1940, p. 11.

DIÁRIO DA TARDE (PR), Curitiba, 14 fev. 1946, p. 3. Hemeroteca digital, Biblioteca Nacional. Disponível em: http://bndigital.bn.gov.br/hemeroteca-digital/. Acesso em: 9 ago. 2021.

DIÁRIO DA TARDE (PR), Curitiba, 14 dez. 1950, p. 3. Hemeroteca digital, Biblioteca Nacional. Disponível em: http://bndigital.bn.gov.br/hemeroteca-digital/. Acesso em: 9 ago. 2021.

DIÁRIO DA TARDE (PR), Curitiba, 15 dez. 1950, p. 3. Hemeroteca digital, Biblioteca Nacional. Disponível em: http://bndigital.bn.gov.br/hemeroteca-digital/. Acesso em: 9 ago. 2021.

DIÁRIO DA TARDE (PR), Curitiba, 14 mar. 1951, p. 3. Hemeroteca digital, Biblioteca Nacional. Disponível em: http://bndigital.bn.gov.br/hemeroteca-digital/. Acesso em: 9 ago. 2021.

DIÁRIO DA TARDE (PR), Curitiba, 16 mar. 1951, p. 3. Hemeroteca digital, Biblioteca Nacional. Disponível em: http://bndigital.bn.gov.br/hemeroteca-digital/. Acesso em: 9 ago. 2021.

DIÁRIO DA TARDE (PR), Curitiba, 19 mar. 1951, p. 3. Hemeroteca digital, Biblioteca Nacional. Disponível em: http://bndigital.bn.gov.br/hemeroteca-digital/. Acesso em: 9 ago. 2021.

ELIAS, Norbert; DUNNING, Eric. A busca da excitação. Lisboa: Difel, 1992.

GERHALDT, Tatiana Engel; SILVEIRA, Denise Tolfo (org.). Métodos de Pesquisa. Porto Alegre: UFRGS, 2009. 120 p. Disponível em: http://www.ufrgs.br/cursopgdr/downloadsSerie/ derad005.pdf. Acesso em: 15 ago. 2021. 
GOELLNER, Silvana Vilodre. Bela, maternal e feminina: imagens da mulher na revista Educação Physica. 1999. 180 f. Tese (Doutorado) - Faculdade de Educação, Universidade Estadual de Campinas, Campinas, 1999. Disponível em: http://hdl.handle.net/10183/2709. Acesso em 18 fev. 2021.

GOELLNER, Silvana Vilodre. Mulheres e futebol no Brasil: descontinuidades, resistências e resiliências. Movimento (Porto Alegre), v. 27, p. e27001, jan. 2021. ISSN 1982-8918. DOI: https://doi.org/10.22456/1982-8918.110157. Disponível em: https://seer.ufrgs.br/Movimento/ article/view/110157/60400. Acesso em: 18 nov. 2021.

GOELLNER, Silvana Vilodre. Mulheres e futebol no Brasil: entre sombras e visibilidades. Revista Brasileira de Educação Física e Esportes, v. 19, n. 2, p.143-151, abr./jun. 2005. Disponível em: http://www.revistas.usp.br/rbefe/article/view/16590/18303. Acesso em 18 fev. 2021.

KNIJNIK, Jorge Dorfman (org.). A mulher brasileira e o esporte: seu corpo, sua história. São Paulo: Mackenzie, 2003. 134 p.

LUCA, Tania Regina de. Fontes Impressas: história dos, nos e por meio dos periódicos. In: PINSKY, Carla Bassanezi (org.). Fontes Históricas. 2. ed. São Paulo: Contexto, 2008. p. 111-154.

MANHÃES, Eduardo Dias. Política de Esportes no Brasil. 2. ed. São Paulo: Paz e Terra, 2002.

MOURÃO, Ludmila. Representação social da mulher brasileira nas atividades físicodesportivas: da segregação à democratização. Movimento (Porto Alegre), v. 6, n. 13, p. 5-18, dez. 2000. DOI: https://doi.org/10.22456/1982-8918.11777 Disponível em: https://seer. ufrgs.br/Movimento/article/view/11777. Acesso em: 10 mar. 2021.

O DIA (PR), Curitiba, 3 jan. 1934, p. 5. Hemeroteca digital, Biblioteca Nacional. Disponível em: http://bndigital.bn.gov.br/hemeroteca-digital/. Acesso em: 9 ago. 2021.

O DIA (PR), Curitiba, 4 jan. 1934, p. 5. Hemeroteca digital, Biblioteca Nacional. Disponível em: http://bndigital.bn.gov.br/hemeroteca-digital/. Acesso em: 9 ago. 2021.

O DIA (PR), Curitiba, 5 jan. 1934, p. 5. Hemeroteca digital, Biblioteca Nacional. Disponível em: http://bndigital.bn.gov.br/hemeroteca-digital/. Acesso em: 9 ago. 2021.

O DIA (PR), Curitiba, 6 jan. 1934, p. 5. Hemeroteca digital, Biblioteca Nacional. Disponível em: http://bndigital.bn.gov.br/hemeroteca-digital/. Acesso em: 9 ago. 2021.

O DIA (PR), Curitiba, 7 jan. 1934, p. 2. Hemeroteca digital, Biblioteca Nacional. Disponível em: http://bndigital.bn.gov.br/hemeroteca-digital/. Acesso em: 9 ago. 2021.

O DIA (PR), Curitiba, 11 ago. 1937, p. 6. Hemeroteca digital, Biblioteca Nacional. Disponível em: http://bndigital.bn.gov.br/hemeroteca-digital/. Acesso em: 9 ago. 2021.

O DIA (PR), Curitiba, 20 ago. 1937, p. 6. Hemeroteca digital, Biblioteca Nacional. Disponível em: http://bndigital.bn.gov.br/hemeroteca-digital/. Acesso em: 9 ago. 2021.

O DIA (PR), Curitiba, 03 abr. 1940, p. 4. Hemeroteca digital, Biblioteca Nacional. Disponível em: http://bndigital.bn.gov.br/hemeroteca-digital/. Acesso em: 9 ago. 2021.

O DIA (PR), Curitiba, 16 abr. 1940, p. 1. Hemeroteca digital, Biblioteca Nacional. Disponível em: http://bndigital.bn.gov.br/hemeroteca-digital/. Acesso em: 9 ago. 2021. 
O DIA (PR), Curitiba, 26 jun. 1940, p. 10. Hemeroteca digital, Biblioteca Nacional. Disponível em: http://bndigital.bn.gov.br/hemeroteca-digital/. Acesso em: 9 ago. 2021.

O DIA (PR), Curitiba, 3 nov. 1940, p. 10. Hemeroteca digital, Biblioteca Nacional. Disponível em: http://bndigital.bn.gov.br/hemeroteca-digital/. Acesso em: 9 ago. 2021.

O DIA (PR), Curitiba, 14 fev. 1941, p. 6. Hemeroteca digital, Biblioteca Nacional. Disponível em: http://bndigital.bn.gov.br/hemeroteca-digital/. Acesso em: 9 ago. 2021.

O DIA (PR), Curitiba, 26 nov. 1950, p. 8. Hemeroteca digital, Biblioteca Nacional. Disponível em: http://bndigital.bn.gov.br/hemeroteca-digital/. Acesso em: 9 ago. 2021.

O DIA (PR), Curitiba, 29 nov. 1950, p. 7. Hemeroteca digital, Biblioteca Nacional. Disponível em: http://bndigital.bn.gov.br/hemeroteca-digital/. Acesso em: 9 ago. 2021.

O DIA (PR), Curitiba, 13 dez. 1950, p. 7. Hemeroteca digital, Biblioteca Nacional. Disponível em: http://bndigital.bn.gov.br/hemeroteca-digital/. Acesso em: 9 ago. 2021.

O DIA (PR), Curitiba, 14 dez. 1950, p. 7. Hemeroteca digital, Biblioteca Nacional. Disponível em: http://bndigital.bn.gov.br/hemeroteca-digital/. Acesso em: 9 ago. 2021.

O DIA (PR), Curitiba, 17 dez. 1950, p. 3. Hemeroteca digital, Biblioteca Nacional. Disponível em: http://bndigital.bn.gov.br/hemeroteca-digital/. Acesso em: 9 ago. 2021.

O DIA (PR), Curitiba, 25 fev. 1951, p. 9. Hemeroteca digital, Biblioteca Nacional. Disponível em: http://bndigital.bn.gov.br/hemeroteca-digital/. Acesso em: 9 ago. 2021.

DIA (PR), Curitiba, 14 mar. 1951, p. 6 e 7. Hemeroteca digital, Biblioteca Nacional.

Disponível em: http://bndigital.bn.gov.br/hemeroteca-digital/. Acesso em: 9 ago. 2021.

O DIA (PR), Curitiba, 15 mar. 1951, p. 7. Hemeroteca digital, Biblioteca Nacional. Disponível em: http://bndigital.bn.gov.br/hemeroteca-digital/. Acesso em: 9 ago. 2021.

O DIA (PR), Curitiba, 16 mar. 1951, p. 6 e 7. Hemeroteca digital, Biblioteca Nacional. Disponível em: http://bndigital.bn.gov.br/hemeroteca-digital/. Acesso em: 9 ago. 2021.

O DIA (PR), Curitiba, 17 mar. 1951, p. 7. Hemeroteca digital, Biblioteca Nacional. Disponível em: http://bndigital.bn.gov.br/hemeroteca-digital/. Acesso em: 9 ago. 2021.

O DIA (PR), Curitiba, 18 mar. 1951, p. 9. Hemeroteca digital, Biblioteca Nacional. Disponível em: http://bndigital.bn.gov.br/hemeroteca-digital/. Acesso em: 9 ago. 2021.

O DIA (PR), Curitiba, 20 mar. 1951, p. 9. Hemeroteca digital, Biblioteca Nacional. Disponível em: http://bndigital.bn.gov.br/hemeroteca-digital/. Acesso em: 9 ago. 2021.

O DIA (PR), Curitiba, 2 jun. 1951, p. 7. Hemeroteca digital, Biblioteca Nacional. Disponível em: http://bndigital.bn.gov.br/hemeroteca-digital/. Acesso em: 9 ago. 2021.

O DIA (PR), Curitiba, 27 dez. 1951, p. 6. Hemeroteca digital, Biblioteca Nacional. Disponível em: http://bndigital.bn.gov.br/hemeroteca-digital/. Acesso em: 9 ago. 2021.

PANDOLFI, Dulce (org.). Repensando o Estado Novo. Rio de Janeiro: Fundação Getúlio Vargas, 1999. 345 p. Disponível em: https://bibliotecadigital.fgv.br/dspace/ handle/10438/6762. Acesso em: 10 mar. 2021.

PRIORI, Angelo et al. História do Paraná: (séculos XIX e XX). Maringá: Eduem, 2012. 234 p. Disponível em: https://static.scielo.org/scielobooks/k4vrh/pdf/priori-9788576285878.pdf. Acesso em: 15 nov. 2021. 
RIBEIRO, Luiz Carlos et al. Descrição arquivística do acervo documental do Conselho Regional de Desportos do Paraná. Acervo, [s. I], v. 27, n. 2, p. 80-92, 24 set. 2014.

Disponível em: http://hdl.handle.net/20.500.11959/brapci/43278. Acesso em: 15 maio 2021.

RIGO, Luiz Carlos et al. Notas acerca do futebol feminino pelotense em 1950: um estudo genealógico. Revista Brasileira de Ciências do Esporte, v. 29, n. 3, p. 173-188, mar. 2008. Disponível em: http://www.revista.cbce.org.br/index.php/RBCE/article/view/217. Acesso em: 15 ma. 2020. 


\section{(I) MOVIMENTO

Abstract: When we temporally compare the milestones in the development of women's and men's soccer, we can notice differences with origins beyond the fields. In an attempt to better understand the phenomenon of women's soccer, this article describes and analyzes its trajectory in Paraná (Brazil) until 1951. For this, some newspapers of the Brazilian Digital Hemeroteca were used, as well as four telegrams found in the Public Archive of Paraná about a request for authorization to carry out a women's soccer match in Curitiba. After analyzing the sources, it was found that women's soccer was linked to artistic practices from 1934 onwards, and that its beginning as a sport in Paraná occurred in 1951 at the Durival de Britto e Silva stadium with two teams from Rio Grande do Sul - Amazonas and Tiradentes - in a context of impositions, contradictions, and civil disobedience.

Keywords: History, 20th century. Soccer. Women.

Resumen: Al comparar los hitos en el desarrollo del fútbol femenino y masculino a lo largo del tiempo, podemos ver diferencias que se originan más allá del campo de juego. En un intento por comprender mejor el fenómeno del fútbol femenino, este artículo describe y analiza su trayectoria en Paraná (Brasil) hasta 1951. Para ello se utilizaron algunas revistas de la hemeroteca digital brasileña y cuatro telegramas encontrados en el Archivo Público de Paraná sobre una solicitud de autorización para realizar un partido de fútbol femenino en Curitiba. Tras analizar las fuentes, se constató que el fútbol femenino estuvo vinculado a prácticas artísticas desde 1934 y que su inicio como deporte en Paraná se dio en 1951, en el estadio Durival de Britto e Silva con dos equipos de Rio Grande do Sul: Amazonas y Tiradentes, en un contexto de imposiciones, contradicciones y desobediencias civiles.

Palabras clave: Historia del siglo XX. Fútbol. Mujeres. 


\section{(10 MOVIMENTO

NOTAS

\section{LICENÇA DE USO}

Este é um artigo publicado em acesso aberto (Open Access) sob a licença Creative Commons Atribuição 4.0 Internacional (CC BY 4.0), que permite uso, distribuição e reprodução em qualquer meio, desde que o trabalho original seja corretamente citado. Mais informações em: https://creativecommons.org/licenses/by/4.0

\section{CONFLITO DE INTERESSES}

Os autores declararam que não existe nenhum conflito de interesses neste trabalho.

\section{CONTRIBUIÇÕES AUTORAIS}

Joana Caroline Corrêa da Silva: Conceptualização, Investigação, Metodologia, Redação - rascunho original.

André Mendes Capraro: Conceptualização, Supervisão, Redação - revisão e edição.

\section{FINANCIAMENTO}

O presente trabalho foi realizado sem o apoio de fontes financiadoras.

\section{COMO REFERENCIAR}

SILVA, Joana Caroline Corrêa da; CAPRARO, André Mendes. O desporto inadequado à natureza feminina: prelúdios do Futebol feminino no Paraná (1934-1951). Movimento, v.28, p. e28007, jan./dez. 2022. DOI: https://doi. org/10.22456/1982-8918.118240. Disponível em: https://seer.ufrgs.br/Movimento/ article/view/118240. Acesso em: [dia] [mês abreviado]. [ano].

\section{RESPONSABILIDADE EDITORIAL}

Alex Branco Fraga*, Elisandro Schultz Wittizorecki*, Ivone Job*, lleana Wenetz ${ }^{* *}$, Mauro Myskiw*, Raquel da Silveira*

*Universidade Federal do Rio Grande do Sul, Escola de Educação Física, Fisioterapia e Dança, Porto Alegre, RS, Brasil.

**Universidade Federal do Espírito Santo, Centro de Educação Física e Desportos (CEFD), Vitória, ES, Brasil. 